\title{
EDUCAÇÃO RURAL E EDUCAÇÃO DO CAMPO: DESAFIOS DA FORMAÇÃO DE PROFESSORES NO BRASIL E NO PIAUÍ
}

\author{
Rural Education and Field Education: challenges for teacher training in Brazil and Piauí
}

\author{
Raimunda Alves Melo ${ }^{1}$ \\ Antonia Dalva França-Carvalho ${ }^{2}$
}

\begin{abstract}
RESUMO: Este artigo é parte de uma pesquisa de doutorado desenvolvida junto ao Programa de Pós-graduação da Universidade Federal do Piauí (UFPI), cujo objeto de estudo foram as mudanças ocorridas na prática educativa de professores de escolas do campo após a participação dos mesmos na Licenciatura em Educação do Campo (LEdoC). O recorte apresentado nesse artigo objetiva apresentar a trajetória de constituição da Educação Rural e da Educação do Campo nos contextos nacional e piauiense. Realizou-se pesquisa de abordagem qualitativa crítica, utilizando-se da análise documental e bibliográfica como procedimento de produção de dados. A leitura histórica das políticas educacionais destinadas às populações camponesas possibilitou-nos conhecer diferentes projetos educativos e de formação de professores desenvolvidos ao longo da história do Brasil, evidenciando a predominância das propostas de Educação Rural e sua inoperância frente aos desafios educacionais do campo. Nesse cenário, a Educação do Campo surgiu como resistência ao modelo de desenvolvimento econômico capitalista; nasceu como uma proposta educativa alternativa para os trabalhadores do campo, fundamentada em seus objetivos de luta, em suas necessidades e anseios.
\end{abstract}

Palavras-chave: Formação inicial de professores. Educação do Campo. Educação Rural.

\begin{abstract}
This article is part of a doctoral research developed with the Postgraduate Program of the Federal University of Piauí (UFPI), whose object of study was the changes in the educational practice of teachers from rural schools after their participation in the Licenciatura in Rural Education (LEdoC). The outline presented in this article aims to present the trajectory of the constitution of Rural Education and Rural Education in the national and Piauí contexts. Research with a qualitative critical approach was carried out, using documentary and bibliographic analysis as a data production procedure. The historical reading of educational policies aimed at the peasant populations allowed us to learn about different educational and teacher training projects developed throughout the history of Brazil, showing the predominance of Rural Education proposals and their ineffectiveness in the face of educational challenges in the countryside. In this scenario, Rural Education emerged as a resistance to the capitalist economic development model; it was born as an alternative educational proposal for rural workers, based on their objectives of struggle, their needs and desires.
\end{abstract}

Keywords: Initial teacher Training. Rural education. Rural Education.

\footnotetext{
${ }^{1}$ Doutora em Educação pela Universidade Federal do Piauí (UFPI). Professora do Curso de Licenciatura em Educação do Campo (LEdoC) da UFPI, Campus Ministro Petrônio Portella (CMPP), em Teresina (PI). Membro do Núcleo de Pesquisa Núcleo Interdisciplinar de Pesquisa em Educação e Epistemologia da Prática Profissional (NIPEEPP). Email: raimundinhamelo@yahoo.com.br

${ }^{2}$ Doutora em Educação pela Universidade Federal do Ceará (UFC). Professora do Departamento de Fundamentos da Educação e do Programa de Pós-Graduação em Educação (PPGEL), do Centro de Ciências da Educação (CCE), Universidade Federal do Piauí (UFPI), Campus Ministro Petrônio Portella (CMPP). E-mail: adalvac@uol.com.br
} 


\section{CONSIDERAÇÕES INICIAIS}

No Brasil, as políticas de formação de professores se apresentam como elementos-chave na implementação das reformas de ensino, concebidas como alternativas para alcançar o desenvolvimento econômico, social e cultural do país, evidenciando o papel estratégico da educação escolar nos projetos governamentais, executados via reformas de ensino, tendo as políticas de formação de professores como elemento-chave para sua implementação. Nesse sentido, a formação de professores possui papel estratégico para o estado capitalista, seja pelas características que são próprias do caráter interventivo estatal, seja pela obrigação dos governos em atender às demandas educacionais reivindicadas por meio das lutas sociais em confronto.

A compreensão das políticas de professores, implica em conhecimento sobre as questões de ordem histórica, econômica, política e social que interferiram e interferem no delineamento das políticas educacionais atuais. Nesse ínterim, situamos a trajetória de constituição da Educação Rural e da Educação do Campo no Brasil e no Piauí, com ênfase nas políticas de formação de professores, partindo de uma dimensão mais ampla, a fim de que possamos analisar o modo como estas vem se organizando pedagógica e politicamente ao longo dos anos.

Com essa finalidade, julgamos ser necessário não perder de vista as questões que, no passado e na atualidade, permearam e permeiam o campo da educação escolar e da formação de professores, a saber: que sociedade deseja-se formar? Qual o perfil de ser humano para atuar nessa sociedade? Que saberes e conhecimentos precisam ter o educador para formar as atuais e as futuras gerações? Como a educação/formação pode contribuir para a construção desse projeto de sociedade?

Realizamos o estudo através do viés epistemológico da pesquisa qualitativa crítica, uma modalidade que permite a inserção do pesquisador no contexto da investigação, aproximando-o do problema a ser pesquisado, bem como, dos interlocutores que vivenciam e compartilham uma dada realidade marcada por diversas experiências profissionais e pessoais, sujeitas a uma relação que se caracteriza pela natureza dinâmica, viva, interativa e contraditória.

Um dos aspectos mais relevantes da pesquisa qualitativa, inspirada pela teoria crítica, refere-se à interpretação das informações, sendo necessário que o pesquisador analise criteriosamente o objeto de estudo, observando o contexto histórico e sua relação com a atualidade, as informações explícitas e implícitas de forma a comunicar a compreensão a respeito do resultado (KINCHELOE; MACLAREN, 2006).

Desse modo, a pesquisa qualitativa crítica contribuiu para evidenciar as diferentes relações de poder e de disputa que envolvem a produção e a socialização de conhecimentos no âmbito da 
formação de professores e estudantes da Educação Básica, bem como, sua relação com a ação humana em prol de mudanças.

Essa investigação é relevante, pois contribui para a produção de conhecimentos científicos e reflexões teóricas sobre processos formativos fundamentados nas concepções de Educação Rural e Educação do Campo, possibilitando aos leitores e pesquisadores, a construção de conhecimentos das políticas implementadas ao longo da história, bem como os desafios da formação de professores para atuação em escolas camponesas.

\section{EDUCAÇÃO RURAL E EDUCAÇÃO DO CAMPO: DIFERENTES PERSPECTIVAS DE FORMAÇÃO DE PROFESSORES}

O processo de formação da sociedade brasileira foi marcado pela visível exclusão das populações rurais das políticas de educação, incluindo as referentes à formação de professores, seja em razão do caráter agrário e extrativista das atividades econômicas desenvolvidas durante o processo de colonização, seja pela prevalência de uma concepção ideológica, oligárquica e elitista de que, para viver no campo, não há necessidade de conhecimentos socializados pela escola, visto que, "gente da roça não carece de estudos. Isso é coisa de gente da cidade” (LEITE, 2002, p. 14).

Com a predominância dessa concepção que, a rigor, norteou as ações governamentais ou a decisão pela ausência dessas mesmas, foi delineado o processo de formação da sociedade brasileira, em meio ao qual as populações rurais foram deixadas à margem das escassas políticas educacionais desenvolvidas no Brasil entre os séculos XVI e XIX. Assim, o processo de colonização do país restringiu a educação formal à elite, sobretudo voltada para as humanidades e as letras ${ }^{3}$. Sobre essa questão, o Parecer CNE/CEB 36/2001 afirma que o ensino desenvolvido no Brasil durante o período colonial "era alheio à vida da sociedade nascente e excluía os escravos, as mulheres e os agregados. Esse modelo atendia aos interesses da Metrópole e sobreviveu, no Brasil, após a expulsão dos jesuítas" (BRASIL, 2001, p. 10).

No tocante à formação de professores, a preparação docente feita pelos jesuítas era rigorosa, incluía estudos de Teologia e de Filosofia. O interessado na profissão de Magistério devia ter, no mínimo, trinta anos de idade e ter boa reputação perante a sociedade. Após a expulsão dos

\footnotetext{
${ }^{3}$ Segundo Heinz (1999, p. 49), no Brasil, a educação escolar herdou de Portugal o caráter religioso e uma "grande valorização da chamada cultura erudita (que teve como resultado a ênfase na formação de bacharéis e homens de letras".
} 
jesuítas pelo Marquês de Pombal, em 1759, esse processo de formação foi interrompido e o ensino foi substituído pelas aulas régias ${ }^{4}$, destinadas apenas à nobreza (OLIVEIRA, 2013).

No Brasil Império, período caracterizado pelo domínio de uma elite conservadora, cuja principal fonte de riqueza era a monocultura de exportação, apenas o ensino de primeiras letras era disponibilizado à população, sem possibilidade de continuidade aos estudos. Mesmo assim, somente parcela desta, tinha acesso a esse ensino, notadamente os mais ricos. Ficavam à margem do processo de escolarização, principalmente, as pessoas mais pobres, entre elas, crianças e jovens camponeses. No que se refere à formação de professores, por força de Ato Adicional de 12 de agosto de 1834 (Constituição Imperial), a responsabilidade pelo ensino e pela formação dos professores foi delegada aos governos das províncias, com predominância de professores leigos ${ }^{5}$ (OLIVEIRA, 2013).

Embora as transformações econômicas, políticas e sociais ocorridas durante a Primeira República, tenham contribuído para o surgimento de um novo imaginário em que a escolarização passou a ser vista como uma alavanca para o progresso do Brasil, resultando inclusive na ampliação do acesso à educação escolar para as classes médias do meio urbano, no meio rural, "o processo escolar continuou descontínuo e desordenado, como sempre fora” (LEITE, 2002, p. 28).

No Piauí, a falta de acesso à educação escolar teve relação direta com as estruturas econômicas, políticas e sociais implantadas no início de seu povoamento, no final do século XVII, quando foram concedidas as primeiras sesmarias ${ }^{6}$, contribuindo para a formação de grandes latifúndios, poderio político e econômico, resultando na ampliação das desigualdades sociais e econômicas que ainda perduram. Segundo Farias et al. (2011, p. 41), esse processo foi pautado na exploração e divisão das terras entre dois grupos distintos: "os agricultores sem-terra e os latifundiários que estenderam poder político e econômico através da formação e perpetuação das oligarquias existentes até hoje na gestão pública piauiense".

\footnotetext{
${ }^{4}$ As Aulas Régias representam a primeira sistematização do ensino público e laico no Reino de Portugal. Sua origem se deve ao marquês de Pombal, estando inserida nas grandes reformas políticas, administrativas, econômicas e culturais que o mesmo implantou no Brasil durante o reinado de Dom José I, resultando na expulsão dos jesuítas do Brasil em 1759. Para sanar a deficiência de estruturas e professores, através de um alvará de 28 de junho de 1759, o governo instituiu as Aulas Régias, atendendo ao ensino elementar de letras e humanidades, bem como, provendo classes de Gramática Latina, Grego e Retórica.

${ }^{5}$ Segundo Oliveira (2013), professores leigos são pessoas, que assumem a função docente de forma improvisada, sem nenhuma formação específica para ensinar os conteúdos de diferentes disciplinas. Os professores leigos existem no Brasil desde a expulsão dos jesuítas em 1759.

${ }^{6}$ Porto (1974), em suas pesquisas, aponta que a concessão de sesmarias no Piauí acompanhava a marcha da conquista e que foi insignificante o número de doações feitas aos verdadeiros povoadores, o que atesta o poder e a força dos sesmeiros naquele período.
} 
A respeito dessa questão, Porto (1974) afirma que o acesso à educação escolar no Piauí, nos séculos XVIII e XIX, era responsabilidade dos mestres-escolas ${ }^{7}$, homens e mulheres que ensinavam principalmente, noções básicas sobre leitura, escrita, operações matemáticas e trabalhos do campo. Essas pessoas eram remuneradas pelas famílias que possuíam algum poder aquisitivo e atendiam na própria residência ou se deslocavam de casa em casa, de fazenda em fazenda, de vila em vila, ensinando crianças e jovens a ler, escrever, fazer contas e realizar alguns trabalhos artesanais e agrícolas. Nestes moldes, as primeiras iniciativas de escolarização desenvolvidas no estado do Piauí eram de cunho particular e excluíam crianças e jovens pobres que viviam tanto nas aglomerações urbanas quanto no meio rural.

Estudos realizados por Saviani (2009, p. 144) apontam que "durante todo o período colonial, desde os colégios jesuítas, passando pelas aulas régias implantadas pelas reformas pombalinas, até os cursos superiores criados a partir da vinda de D. João VI em 1808”, a preparação de docentes não era uma preocupação governamental explícita. Esse autor reforça que foi somente com a aprovação da Lei das Escolas de Primeiras Letras, promulgada em 15 de outubro de 1827, que a formação de professores apareceu, pela primeira vez, na agenda política daquela época. “Ao determinar que o ensino, nessas escolas, deveria ser desenvolvido pelo método mútuo ${ }^{8}$, a referida lei estipulava no artigo $4^{\circ}$ que os professores deveriam ser treinados nesse método, às próprias custas, nas capitais das respectivas províncias" (SAVIANI, 2009, p. 144).

Notemos que, nesse período, a referida lei eximia o poder público da responsabilidade pela preparação dos professores, atribuindo aos docentes, os encargos pela própria formação. Infelizmente, essa ainda é uma situação bastante presente no Brasil, uma vez que o acesso ao Ensino Superior em instituições privadas é uma das principais vias de acesso à formação de professores. Segundo Abrucio (2016, p. 14), “quase 80\% dos alunos de pedagogia estudam em faculdades particulares, grande parte em cursos noturnos - e quase metade dos estudantes das licenciaturas também se encontram nessa situação".

\footnotetext{
${ }^{7}$ Ver o trabalho: A arte de desasnar crianças no sertão Piaui $(1890$ - 1930), da pesquisadora Maria Alveni Barros Vieira (s./d.). Segundo ela, remanescentes da fase primária da colonização, os mestre-escola tiveram uma participação significante na educação das crianças brasileiras. Existia no sertão oitocentista, duas maneiras de exercer o ofício de mestre-escola. O mestre de cátedra erradia, mestre ambulante que vagava pelos centros mais populosos do Piauí em busca de sua clientela. $\mathrm{O}$ mestre de cátedra cativa que recebia seus alunos, sem ter que se deslocar de sua residência. $\mathrm{O}$ pagamento era feito, muitas vezes, com gêneros alimentícios, além de animais de pequeno porte, como galinhas, porcos e ovelhas.

${ }^{8}$ Segundo Saviani (2009), proposto e difundido pelos ingleses Andrew Bell, pastor da Igreja Anglicana e Joseph Lancaster, da seita dos Quakers, o método mútuo, também chamado de monitorial ou lancasteriano, se baseava no aproveitamento dos alunos mais adiantados como auxiliares do professor no ensino de classes numerosas. O método supunha regras pré-determinadas, rigorosa disciplina e a distribuição hierarquizada dos alunos sentados em bancos dispostos num salão único e bem amplo. De uma das extremidades do salão, o mestre, sentado numa cadeira alta, supervisionava toda a escola, em especial os monitores. Avaliando continuamente o aproveitamento e o comportamento dos alunos, esse método erigia a competição em princípio ativo do funcionamento da escola. Os procedimentos didáticos tradicionais permanecem intocados.
} 
No cenário camponês, durante o período colonial, a situação era ainda mais precária, constituindo-se, historicamente, "sob o signo da precariedade física, administrativa e pedagógica, evidencia a presença de um professor qualificado na condição de "leigo" como indicativo da ausência e/ou escassez de uma formação adequada para o exercício da profissão" (MOLINA; ANTUNES-ROCHA, 2014, p. 221). Dessa forma, as poucas iniciativas de ensino das primeiras letras, espalhadas, geralmente, pelas áreas rurais mais povoadas, eram assistidas por professores sem habilitação para o exercício da profissão, os chamados professores leigos, cuja escolarização que possuíam era apenas a quarta série do primário.

No século XXI, o grande desafio tem sido assegurar a formação em nível superior para todos os professores do Brasil. A respeito dessa questão, comporta citar resultados de estudo realizado pelo Instituto de Pesquisa Econômica Aplicada (IPEA), denominado Professores da educação básica no Brasil: condições de vida, inserção no mercado de trabalho e remuneração (2015-2017), segundo o qual, nas escolas rurais, "a situação é mais difícil, pois as condições para a contratação e a permanência docente na área exigem a adoção de medidas de exceção, como relaxar certas exigências de formação. Sem tais medidas, pode ser inviável manter escolas para essas populações" (MATIJASCIC, 2017, p. 26). Segundo essa pesquisa, o índice de professores atuando em áreas rurais e com formação apenas em nível médio é de 30,9\% na rede estadual e de 41,4\% na rede municipal.

O fato é que, ao longo da história, a educação escolar dos povos do campo foi construída a partir do descaso governamental, da escassez de políticas públicas capazes de dar conta da complexidade do contexto rural e dotação financeira insuficiente para atendimento das demandas que possibilitem a existência e a manutenção de escolas em todos os níveis, etapas e modalidades de ensino, com qualidade, incluindo a formação dos professores.

Embora o Brasil seja um país que tenha construído sua história econômica, política e cultural a partir das relações de exploração da terra e dos seus sujeitos, estudos apontam que até as primeiras décadas do século XX, a educação escolar era destinada apenas a uma minoria privilegiada pertencente à elite, excluindo as populações camponesas (BRASIL, 2005). Essa mesma exclusão educacional ainda é bastante presente no Estado do Piauí que, apesar de possuir economia predominantemente agrícola, pecuarista e extrativista (mineral e vegetal), a educação das pessoas que residem no campo ainda é desenvolvida sob a égide da injustiça e desigualdades educacionais (SILVA; SOARES, 2016), evidenciadas pelos elevados índices de analfabetismo, fechamento de escolas, entre outros.

Nas primeiras décadas do século XX, acontecimentos políticos, econômicos e sociais deram um novo perfil à sociedade brasileira. "A quebra da Bolsa de Nova York, em 1929, 
mergulhou o Brasil na crise do café, mas, em contrapartida, encaminhou o país para o desenvolvimento industrial [...], alterando assim o comando da nação, que passou da elite agrária aos novos industriais" (LIBÂNEO, 2012, p. 151). Nesse período, também houve crescente urbanização motivada, sobretudo, pelo início da industrialização e consequente, êxodo rural.

Tendo como principais atividades econômicas, a pecuária, a agricultura e o extrativismo, atividades essas desenvolvidas por pessoas com pouca ou nenhuma escolaridade, o Piauí apresentava realidade diferente de outros estados brasileiros em que as atividades industriais demandavam a preparação de pessoal mais qualificado, como afirma Reis (2011, p. 76): “O ciclo de desenvolvimento econômico do Piauí foi a base da pecuária extensiva colocando o latifúndio como elemento primordial desse processo, sem se preocupar com a modernização tecnológica". A predominância desse modelo econômico contribuiu para que o processo de escolarização da população piauiense, mesmo nas primeiras décadas do século XX, tenha sido caracterizado pela ausência de políticas educacionais satisfatórias para as populações camponesas.

Como reflexo desse problema, dados do Plano Estadual de Educação (Lei 6.733, 17 de dezembro de 2015), apresentados pelos autores Silva; Soares (2016), apontam que, apesar do Estado ter grande contingente populacional habitando no campo, mais precisamente 1.067.401 de pessoas, quantidade superior a um terço da população, "as condições de acesso à educação têm sido negligenciadas e mesmo desrespeitadas, visto que $22,9 \%$ dos piauienses são analfabetos, sendo que a maioria deles se concentra no campo" (SILVA; SOARES, 2016, p. 48).

Outrossim, ressaltamos que em outras regiões do Brasil, o advento das mudanças ocorridas nas primeiras décadas do século XX contribuiu para que a educação escolar ganhasse mais importância, uma vez que, o novo modelo de desenvolvimento econômico exigia condições mínimas de escolarização, diferentemente da estrutura oligárquica rural anterior, na qual a necessidade de instrução não era sentida nem pela população, nem pelos poderes constituídos.

No campo, essas transformações contribuíram para o surgimento do ruralismo pedagógico, uma ideologia que fazia oposição ao industrialismo e ao urbanismo, o que ocasionou o surgimento de iniciativas educacionais de caráter assistencial, as quais defendiam a necessidade de uma formação para o trabalho agrícola, uma educação prática, utilitária e adaptada à vida rural. Segundo Araújo (2011, p. 238), “originário do domínio coronelista, o ruralismo sustentava-se em ideias que contrapunham os mundos camponês e citadino. Tal visão situava a vida camponesa como lócus ideal para a formação de homens perfeitos nos aspectos físico, moral e social”.

O nascimento e a expansão do ruralismo pedagógico também foi motivado pelo grave estado educacional do Brasil, quanto ao nível de escolarização das populações camponesas, considerado como um entrave para a pretensão do país em despontar como nação industrializada 
e pela crescente urbanização provocada pelo início da industrialização, tendo como consequência, o aumento do movimento de correntes migratórias, que na época provocavam preocupações ao poder público.

Dessa forma, as motivações para a expansão de escolas no campo, a partir de 1930, não se voltavam para os interesses e as necessidades das populações camponesas de acesso à educação escolar, mas para a resolução de problemas urbanos e de interesse econômico e político do Estado, uma vez que "a educação é uma constante em todas as culturas e sociedades e, de certa forma, reflete - intenções ideologias - dos dirigentes políticos administrativos" (LEITE, 2002, p. 17).

O delineamento dessa proposta foi delegado à elite intelectual brasileira, representada pelos educadores Alberto Torres, Silvio Romero, Belizário Pena e Sud Mennuci. Este último, responsável por colocar em realce as ideias sobre o estabelecimento de um projeto escolar para o Brasil, somando seus esforços aos intelectuais que, nos anos de 1930, conduziram os rumos do ruralismo pedagógico em nosso país.

Segundo Matos (2004), Mennucci acreditava que os problemas econômicos e sociais do campo deviam-se à ausência de uma educação rural e profissionalizante e pela inadequação do ensino à realidade brasileira. Para esse educador, "a escola nacional deveria levar o brasileiro a se tornar um homem adaptado ao meio em que vivia, fornecendo-lhe uma mudança de mentalidade capaz de fazê-lo sentir e acreditar em sua força criadora, na busca crescente da melhoria de vida" (ARAÚJO, 2011, p. 241). No entanto, nesse período, outra proposta educacional também estava em disputa, pois, educadores como Fernando de Azevedo, Almeida Júnior, Abgar Renault, Teixeira de Freitas e Lourenço Filho projetavam uma escola comum para todos os alunos e alertavam sobre o risco de que as escolas situadas no campo se transformassem em espaços limitados à vida rural (MOLINA; ANTUNES-ROCHA, 2014).

Foi nesse período que, pela primeira vez, no Brasil, foi discutida a necessidade de uma formação específica para os professores de escolas rurais, visto que as propostas desenvolvidas naquela época estavam fortemente influenciadas pelo projeto nacionalista e sua materialização demandava um profissional formado a partir dos ideais preconizados pelo ruralismo pedagógico. A exemplo dessa questão, em 1942, o Ministério da Educação e Cultura criou o Plano Nacional de Ampliação e Melhoria da Educação Primária e Normal. Para área rural este plano previa “a construção de escolas com residências para professores, cursos de aperfeiçoamento para professores rurais e a construção de escolas normais rurais com internatos, quando necessário, nas diversas unidades federais" (SOUZA, 2015, p. 97).

O ruralismo pedagógico, ao defender uma proposta de formação de professores que primava pelas especificidades das escolas rurais, representou uma primeira tentativa de superação 
de um modelo único e universal de professor, a exemplo do que defendem atualmente os propositores da Educação do Campo. No entanto, naquele período, sobressaiu-se a proposta de que todo professor devia dispor dos mesmos saberes e conhecimentos que o capacitasse para atuar em escolas urbanas ou rurais, independentemente da diversidade dos coletivos humanos e da realidade em que estivessem inseridos.

No cenário brasileiro, o ideário de uma educação vocacionada, proposta pelo ruralismo pedagógico perpetuou até a década de 50, comungando com interesses políticos e econômicos do governo de conter as ondas migratórias e, ao mesmo tempo, perpetuando uma visão ambiciosa do capitalismo, particularmente o empresariado industrial, interessado na mão de obra barata dos trabalhadores rurais. De todo modo, não se pode negar que essa iniciativa contribuiu para a expansão e a ampliação da escola primária rural no Brasil. "Após essa década houve iniciativa desenvolvida pelo movimento extensionista ${ }^{9}$, cujo objetivo era elevar o padrão de vida, de saúde e de educação das comunidades rurais, contudo, sem evidenciar e focalizar o papel da escola" (SILVA, 2011, p. 72).

Segundo Cortez (2006), no Piauí, a partir dos anos de 1950, foram desenvolvidas algumas ações para formação de docentes, a exemplo da realização de exames de suficiência ${ }^{10}$. Contudo, estes não atingiram os professores leigos rurais, pois não houve compatibilização entre a realidade legal e a situação desses docentes. É notório que essas iniciativas fragmentadas tinham caráter emergencial e assistencialista, não atendiam a contento às necessidades formativas dos professores e nem consideravam as especificidades do contexto camponês.

No Brasil, a partir da década de 1950-1960 emergiram e se consolidaram movimentos ligados às mais variadas instâncias sociais. Entre os mais importantes, citamos o Movimento de Cultura Popular (MCP), que contou com Paulo Freire, entre seus integrantes; o Movimento de Educação de Base (MEB), criado pela Conferência Nacional dos Bispos no Brasil (CNBB); e os Centros Populares de Cultura (CPC), criados pela União Nacional dos Estudantes (UNE). Esses movimentos sociais, sindicais e pastorais, passaram a desempenhar papel determinante na formação política de lideranças do campo e na luta pela reivindicação de direitos ao acesso à terra, à saúde, à moradia e, principalmente, à educação.

\footnotetext{
${ }^{9}$ Segundo Silva (2011), após o fracasso da educação no campo na versão do ruralismo pedagógico, surgiu o movimento extensionista no Brasil, organizado a partir da perspectiva de educação extraescolar, identificada como educação informal.

${ }^{10}$ Exame Suficiência eram exames realizados pelas Escolas Normais, Institutos de Educação e Faculdades de Filosofia a que eram submetidos os professores leigos ou candidatos ao magistério para efeito de comprovação de conhecimentos exigidos para a função e autorização, a título precário, lecionarem nas escolas primária e secundária (CORTEZ, 2006).
} 
Foi nesse contexto que o educador Paulo Freire demarcou uma proposta de educação libertadora para o Brasil, confirmando-se, pela primeira vez, e de forma consistente, uma pedagogia anunciada nas classes populares e trabalhadoras e que permanece viva no Brasil e no mundo. As concepções originárias da Educação do Campo têm seus alicerces fundamentados na Pedagogia do Oprimido ${ }^{11}$ e em toda a tradição pedagógica decorrente das experiências da Educação Popular ${ }^{12}$ proposta por Freire e na Pedagogia do Movimento $^{13}$, desenvolvida a partir das experiências educativas dos próprios movimentos sociais, sobretudo, do Movimento dos Trabalhadores Rurais Sem Terra (MST). Nesse sentido, os primeiros passos para a implantação de propostas formativas, delineadas a partir dos interesses das populações, visando à emancipação política e à criticidade dos mesmos, foram dados na década de 60 , tendo à sua frente esse educador brasileiro.

Porém, em meados da década de 60 , houve um retrocesso na política educacional brasileira, provocado pela instituição do golpe militar de 1964, época que se caracterizou pelo fechamento dos canais de participação, exílio de educadores e lideranças comunitárias comprometidas com a educação das classes populares, a exemplo de Paulo Freire e, ainda, o controle dos bens educacionais e sociais. Segundo Pimenta; Lima (2012, p. 14), os anos que sucederam o golpe militar foram marcados pelo controle cada vez mais burocrático do trabalho dos professores, "evidenciando uma política ineficaz para a democratização do ensino, sem resolver a exclusão social no processo de escolarização".

Santana (2011) afirma que, nesse período, a zona rural piauiense era caracterizada pela escassez de políticas educacionais e consequente, elevação do número de pessoas analfabetas. Ressalta que, parte da população era atendida por programas com os quais o Piauí efetivou convênios na época, como o Movimento de Educação de Base $(\mathrm{MEB})^{14}$ e o Movimento Brasileiro

\footnotetext{
${ }^{11}$ Pedagogia do Oprimido é um dos mais conhecidos trabalhos do educador Paulo Freire. O livro propõe uma pedagogia com uma nova forma de relacionamento entre professor, estudante e sociedade. Nesta obra, Freire inclui uma detalhada análise de classes marxistas em sua exploração da relação entre os que ele chama de "oprimido e opressor". Ver o trabalho de Arroyo (2012).

${ }^{12}$ A origem da Educação Popular decorre do modo de produção de vida em sociedade no capitalismo, na América Latina e também no Brasil, emerge a partir da luta de classes populares em defesa de seus direitos. Trata-se de uma educação comprometida e participativa, orientada pela perspectiva de realização de todos os direitos do povo. Sua principal característica é utilizar o saber da comunidade como matéria prima para o ensino. Ver o trabalho de Paludo (2012).

${ }^{13}$ A Pedagogia do Movimento identifica uma síntese de compreensão do trabalho de educação desenvolvido pelo Movimento dos Trabalhadores Rurais Sem Terra (MST), produzida por ele próprio desde sua dinâmica histórica. Como conceito específico, é concebida como processo formativo do sujeito sem terra para além de si mesmo. Ver o trabalho de Caldart (2012).

${ }^{14}$ Segundo Cortez (2006), o MEB, influenciado por ações da Igreja Católica e grupos de alfabetização de adultos e de educação popular foi desenvolvido com recursos do Ministério da Educação e Cultura e da SUDENE, com a finalidade de autopromoção das populações rurais.
} 
de Alfabetização (MOBRAL) ${ }^{15}$, que proporcionavam educação tanto para zona urbana, como para zona rural, incluindo a distribuição de materiais didáticos e formação para professores leigos. Esse período também foi caracterizado tanto por um silenciamento nas políticas públicas quanto na produção acadêmica no que diz respeito à educação escolar e à formação docente no contexto rural.

Dialogando com os ideais políticos e econômicos dos militares, nas décadas de 60/70, predominou um modelo de desenvolvimento econômico que se destacou pela valorização da monocultura, construção de hidrelétricas, industrialização, implantação de pacotes tecnológicos adotados pelos militares, cujas consequências intensificaram as lutas de posseiros e seringueiros pelo direito à terra e à sobrevivência no campo.

A adoção de um modelo de desenvolvimento modernizante, a partir do golpe militar de 1964 limitou a atuação dos professores no campo e deu origem a novos desafios, tendo em vista que uma das premissas educacionais imposta pelo novo modelo era forjar consciências submissas, que alimentassem as engrenagens do modelo de desenvolvimento proposto. Como resultado dessa política de desenvolvimento econômico e recessão de direitos sociais, no final dos anos 70, a escola rural voltou a ocupar lugar nos índices de analfabetismo evidenciados pelas pesquisas realizadas naquele período, fato que provocou a criação de projetos de formação de curta duração para certificação e/ou atualização dos docentes leigos (MOLINA; ANTUNES-ROCHA, 2014).

Cortez (2006) afirma que as políticas de formação de professores desenvolvidas nos anos 1970, no Piauí, eram caracterizadas por ações de capacitação do magistério leigo rural em nível pedagógico por meio da implantação do Pedagógico Parcelado ${ }^{16}$, seguindo-se as experiências dos Projetos LOGOS I ${ }^{17}$ e LOGOS $\mathrm{II}^{18}$, a partir de estudos realizados através de módulos.

Estudos de Gonçalves (2015) constataram que no período de 1971 a 1989, a profissão docente no meio rural piauiense foi influenciada por um conjunto de fatores, entre os quais, se

15 O MOBRAL foi criado pela lei no 5.379 de 15 de Dezembro de 1967 e deveria escolarizar pessoas com idades acima de 14 anos. O plano a ser executado pretendia atingir a 11.400 .000 analfabetos, entre 1968 e 1971, pra que se pudesse pensar na extinção do analfabetismo até 1975.

16 Objetivou complementar a qualificação dos professores leigos dos cursos de emergência, contudo, tinha a limitação de não poder atender grande parte do professorado leigo rural pelas suas características metodológicas, embora fosse eficiente qualitativamente (CORTEZ, 2006).

${ }^{17}$ Criado pelo Departamento de Ensino do Ministério da Educação, o Projeto Logos I tinha como objetivo qualificar os professores não-titulados no $1^{\circ}$ grau com formação pedagógica de base, sem oferecer habilitação ao magistério, era desenvolvido em módulos, a distância, sem necessidade de tirar os professores da sala de aula (FUSARI et al., 1990).

18 O Projeto Logos II tinha como objetivo formar professores leigos em regime emergencial, com habilitação em segundo grau para exercício do magistério. Era desenvolvido em sistema modular, por meio de atividades diversificadas e flexíveis, nas quais o aluno estabelecia seu próprio ritmo de aprendizagem sendo que os encontros com o orientador de ensino eram mensais, quando aconteciam também as aplicações de testes (FUSARI et al., 1990). 
destacam as exigências e as possibilidades de formação para atuação na escola rural através de Programas como Promunicípio ${ }^{19}$, Prolonordeste ${ }^{20}$, Pronasec Rural ${ }^{21}$, Logos I, Logos II, Edurural ${ }^{22}$, entre outros. Nesse período, também ocorreu a estruturação dos Órgãos Municipais de Educação e debates em torno de salários, influenciando no exercício docente e na construção da profissão. Não se pode negar que essas políticas contribuíram de algum modo com o processo de formação dos professores, contudo, tratavam-se de ações pontuais, fragmentadas, aligeiradas que dialogavam com as perspectivas da Educação Rural e não com as proposições da Educação do Campo apresentadas na década de 1990.

Em âmbito nacional, esse período foi marcado pelo início e amadurecimento, respectivamente, da luta em prol da redemocratização do país, conscientização da população e reivindicação de direitos, que culminaram com a promulgação da Constituição de 1988. Nesse cenário, situamos a Lei no 9.394/96, que definiu as Diretrizes e Bases da Educação Nacional, propondo, em seu artigo 28 , medidas de adequação da escola à vida no campo, questão não contemplada anteriormente em sua especificidade. A partir de então, a educação do povo do campo conquistou o reconhecimento de sua diversidade e de suas singularidades.

Em decorrência da aprovação da Constituição de 1988 e da LDB 9.394/96, observamos um incremento nas políticas educacionais no Brasil, priorizando ações que visam atender demandas sociais propostas em décadas anteriores, como a universalização do Ensino Fundamental, ampliação das matrículas na Educação Infantil e Ensino Médio, criação de fundos de financiamento, obrigatoriedade do acesso à escola (dos 4 aos 17 anos), implantação de programas de complementação de renda que incentivam a frequência e a permanência de crianças e jovens na escola, entre outros.

\footnotetext{
${ }^{19}$ Segundo Gonçalves (2015), o Promunicípio foi implantado no Piauí em 1977. Seu objetivo era prestar assistência técnica e financeira aos municípios; montar uma equipe municipal de educação; oferecer às unidades escolares da zona rural material e equipamento necessário ao seu regular funcionamento; e atualizar pessoal técnico pedagógico e administrativo dos municípios selecionados para sua implantação.

${ }^{20}$ O Prolonordeste, no que se refere à educação, tinha como objetivo "promover a melhoria quantitativa e qualitativa do ensino na zona rural; direcionar o ensino de $1^{\circ}$ e $2^{\circ}$ graus em suas áreas de atuação no sentido de preparar, em médio prazo mão-de-obra para o setor primário da economia; e integrar as escolas em sua área de contexto (GONÇALVES, 2015).

${ }^{21}$ O Pronasec Rural objetivava proporcionar, de modo integrado à política de desenvolvimento agropecuário, oportunidades de educação básica, combinadas com diversas modalidades de formação especial, notadamente às que se referem à educação para o trabalho, ao fortalecimento da organização social e econômica, ao desenvolvimento cultural da população e ao desenvolvimento comunitário (GONÇALVES, 2015).

22 Segundo Gonçalves (2015), esse Programa objetiva a avaliação e a reformulação da Proposta Curricular Rural e a elaboração de Materiais de Ensino-Aprendizagem adequados à Proposta Curricular Rural. No Piauí, no período de execução, entre 1981 e 1982, o programa qualificou 1.000 professores leigos em nível de $8^{a}$ série do $1^{\circ}$ grau.
} 
Com a promulgação da Lei das Diretrizes e Bases, LDB 9.394/96, a área da formação de professores passou a se configurar como um dos temas mais discutidos no âmbito das políticas educacionais. $\mathrm{O}$ art. 62 dessa Lei determina que a formação de docentes para atuar na educação básica "far-se-á em nível superior, em curso de licenciatura plena, admitida, como formação mínima para o exercício do magistério na Educação Infantil e nos cinco primeiros anos do Ensino Fundamental, oferecida em nível médio, na modalidade normal” (BRASIL, 1996, p. 37).

Em consequência desses dois dispositivos legais (Constituição Federal de 1988 e LDB 9.394/96), a carreira docente incorporou outras exigências, como o acesso por via de concursos públicos, a necessidade de planos de cargo, carreira e salário, a responsabilidade dos gestores públicos pela implementação de políticas destinadas à formação de professores em nível médio e superior, entre outras. Segundo Freitas (2002, p. 137), esse período também foi caracterizado por um processo de flexibilização curricular e adequação do ensino superior às novas demandas “oriundas do processo de reestruturação produtiva, objetivando adequar os currículos aos novos perfis profissionais resultantes dessas modificações".

Nas décadas de 1980, 1990 e nos primeiros anos do século XXI, no Estado do Piauí, os municípios continuaram desenvolvendo os Projetos Logos I, Logos II e Edurural ${ }^{23}$. Nos primeiros anos do século XXI foram desenvolvidos os Programas de Formação de Professores PROFORMAÇÃO ${ }^{24}$ e PROINFANTIL ${ }^{25}$, implantados nos anos 2000 e 2004, respectivamente, ambos destinados à formação para o Magistério em nível médio, oferecidos para professores em exercício nos sistemas municipais e estaduais de educação, que não possuíam a formação em nível pedagógico.

Na década de 90, a formação em nível superior, através de Cursos de Licenciatura Plena foi predominantemente ofertada pela Universidade Estadual do Piauí (UESPI), por meio de cursos realizados em período especial (período de férias) através de convênio com o Estado e com as Prefeituras. Ao tratar sobre a caracterização dessas políticas, Freitas (2002, p. 148) afirma que “todo

\footnotetext{
${ }^{23}$ Segundo Gonçalves (2015), o Edurural tinha como objetivos a avaliação e a reformulação da Proposta Curricular Rural e a elaboração de Materiais de Ensino-Aprendizagem adequados à Proposta Curricular Rural. No Piauí, no período de execução, entre 1981 e 1982, o programa qualificou 1.000 professores leigos em nível de $8^{a}$ série do $1^{\circ}$ grau.

${ }^{24}$ O PROFORMAÇÃO (Programa de Formação de Professores em Exercício), na modalidade de educação a distância surgiu, como uma resposta dentre as diversas alternativas para o atendimento da legislação. Trata-se de um curso de nível médio com habilitação para o magistério destinado aos professores sem habilitação mínima (terceiro ou quarto ano pedagógico) que atuam nas quatro séries iniciais do ensino fundamental e educação infantil. Tem duração de dois anos, organizado em quatro módulos semestrais. Foi desenvolvido especialmente para atender professores dos Estados das Regiões Norte, Nordeste e Centro Oeste. É um programa que foi projetado através de uma parceria entre União, Estados e Municípios, onde cada parte colabora significativamente na sua execução (CUNHA, 2000, p. 35).

25 Criado pela SECADI no ano de 2004, p Programa PROINFANTIL é um curso semipresencial de formação em Ensino Médio, na modalidade Normal, emergencial, oferecido para professores em exercício nos sistemas municipais e estaduais de ensino. Tem duração de 2 anos, perfazendo um total de 3.392 horas, distribuídas em quatro módulos semestrais de 848 horas cada um. O curso confere diploma para o exercício da docência na Educação infantil.
} 
esse processo tem se configurado como um precário processo de certificação e/ou diplomação e não qualificação e formação docente para o aprimoramento das condições do exercício profissional"'.

No final da década de 1990, expandiram-se os espaços públicos de debate sobre educação dos povos do campo, através da ação dos movimentos políticos, principalmente, do Movimento por uma Educação Básica do Campo, cujas reivindicações deram suporte a importantes conquistas no âmbito da regulamentação de políticas públicas para a área. Eventos como o I Encontro de Educadores e Educadoras da Reforma Agrária (ENERA), realizado em 1997, organizado pelo Movimento dos Trabalhadores Sem Terra (MST), com o apoio da Universidade de Brasília (UnB), entre outras instituições, foi um dos primeiros nessa categoria de mobilização. Duas importantes conquistas foram alcançadas a partir desse evento: o Programa Nacional de Educação na Reforma Agrária (PRONERA) ${ }^{26}$ e o desafio de pensar uma proposta de educação pública para as escolas do campo, que considerasse aspectos políticos, econômicos e culturais do povo do campo: a Educação do Campo (CALDART, 2004).

Assim, surgiu a Educação do Campo, originada nos movimentos sociais camponeses, mediante diversas lutas pela construção de uma sociedade sem desigualdades e com justiça social, cujas estratégias de resistência objetivam manter seus territórios de vida, trabalho e identidade, evidenciando uma clara reação ao histórico conjunto de ações educacionais denominadas Educação Rural, que precarizaram o quadro de escolarização no campo e também, contribuíram para perpetuar as desigualdades sociais no território camponês.

De acordo com Silva (2005, p. 34), a Educação Rural é caracterizada pela promoção de campanhas, cujo objetivo é formar mão de obra para a agricultura moderna ou para o trabalho urbano. Essa concepção orienta-se por uma lógica desinteressada da vida do campo, associada a campanhas predominantemente marcadas pela "escola de primeiras letras" que, de acordo com este autor, é uma escola descontextualizada e precária, que não consegue atender adequadamente à população rural.

É válido salientar que o Eixo 2 do Programa Nacional de Educação do Campo (PRONACAMPO $)^{27}$ objetiva apoiar a formação inicial de professores em exercício na Educação

\footnotetext{
26 O PRONERA, criado em 1998, tem como objetivo geral fortalecer a educação nas áreas de Reforma Agrária, estimulando, propondo, criando, desenvolvendo e coordenando projetos educacionais, utilizando metodologias voltadas para a especificidade do campo tendo em vista contribuir para a promoção do desenvolvimento sustentável. ${ }^{27}$ Conjunto de ações articuladas que visam assegurar a melhoria do ensino nas redes existentes, bem como, a formação dos professores, produção de material didático específico, acesso e recuperação da infraestrutura e qualidade da educação no campo em todas as etapas e modalidades - Decreto $n^{\circ} 7.352 / 2010$. Instituído por meio da Portaria $\mathrm{N}^{\circ}$ 86, de $1^{\circ}$ de fevereiro de 2013 constitui-se de quatro eixos: Eixo I - Gestão e Práticas Pedagógicas, Eixo II - Formação de Professores, Eixo III - Educação de jovens e adultos, Educação Profissional e Tecnológica e Eixo IV Infraestrutura Física e Tecnológica.
} 
do Campo e quilombola, por meio dos Cursos de Licenciatura em Educação do Campo ofertados pelas Universidades Federais e Institutos Federais de Educação, Ciência e Tecnologia, enfatizando também, a disponibilização de cursos de licenciatura para professores do campo, na modalidade presencial e a distância, no âmbito do Plano Nacional de Formação de Professores da Educação Básica (PARFOR/CAPES), contemplando maior contingente de cursistas com a expansão dos polos da Universidade Aberta do Brasil (UAB).

Como proposta de formação de professores em disputa, o Curso de Licenciatura em Educação do Campo, criado em 2005, volta-se, especificamente, para a formação de educadores para a docência nos anos finais do Ensino Fundamental e Ensino Médio nas escolas rurais, na perspectiva da Educação do Campo, cuja matriz formativa explicita o projeto de sociedade, de campo e de escola que se deseja construir, o perfil do educador e da formação necessária para que este desenvolva práticas educativas coerentes com os princípios e valores que estruturam essa concepção. O Movimento da Educação do Campo $^{28}$ propõe que os processos formativos desse curso sejam críticos, contextualizados, organizados por meio de propostas que considerem o desenvolvimento do território camponês, aliado a princípios que permeiem o Projeto PolíticoPedagógico (PPP) das escolas.

Trata-se de uma política pública que resulta da luta dos movimentos sociais apresentadas ao Estado pelos movimentos sociais, cuja reivindicação por uma política pública específica, para dar suporte e garantir a formação de educadores do campo, teve início ainda com a realização da Primeira Conferência Nacional por uma Educação Básica no Campo, em 1998, e se consolidou como uma das prioridades requeridas por esse mesmo Movimento ao término da Segunda Conferência Nacional por uma Educação do Campo, realizada em 2004, conforme mencionado anteriormente.

O Curso de Licenciatura em Educação do Campo (LEdoC), desenvolvido por 42 universidades brasileiras, possui as seguintes diretrizes: a) seu objeto é a escola de Educação Básica, com ênfase na organização das escolas e no trabalho pedagógico para os anos finais do Ensino Fundamental e do Ensino Médio; b) seu objetivo é preparar educadores para atuarem na docência, na gestão de processos educativos escolares e na gestão de processos educativos comunitários; c) sua organização curricular prevê etapas presenciais (equivalentes a semestres regulares), ofertadas em regime de alternância entre tempo escola e tempo comunidade; d) sua matriz curricular

\footnotetext{
${ }^{28}$ Segundo Silva (2011), o Movimento da Educação do Campo, composto por diferentes representações dos movimentos sociais e sindicais, pesquisadores e professores da área, surgiu no final da década de 90 com o objetivo de refletir, expor a situação do povo do campo no Brasil, suas perspectivas e experiências, buscando a concretização de novas políticas para o campo, que possam contemplar projetos populares de desenvolvimento da população que reside nessas áreas.
} 
desenvolve uma estratégia multidisciplinar de trabalho docente, organizando os componentes curriculares a partir da áreas do conhecimento (MOLINA, 2015).

Além da LEdoC, a formação de professores em nível superior para atuação nas escolas do campo vem sendo impulsionada por políticas como o Programa Universidade para Todos (PROUNI), o Fundo de Financiamento Estudantil (FIES), a Universidade Aberta do Brasil (UAB), criada em 2006 e pela instituição do Plano Nacional de Formação da Educação Básica (PARFOR), voltado à licenciatura e à formação pedagógica.

O Movimento da Educação do Campo alerta que essas propostas são caracterizadas pela diversificação e flexibilização da oferta dos cursos, com o objetivo de atender à crescente demanda de profissionais para o Magistério na Educação Básica com formação em nível superior. Tratamse de propostas genéricas que não dialogam com as proposições da Educação do Campo e que são fortemente influenciadas pelas políticas neoliberais e ajustadas aos interesses econômicos do mercado, cuja consequência maior é a precarização da formação docente.

\section{CONSIDERAÇÕES FINAIS}

Este artigo objetivou apresentar a trajetória de constituição da Educação Rural e da Educação do Campo nos contextos nacional e piauiense. A análise histórica de políticas educacionais destinadas às populações camponesas possibilitou-nos conhecer diferentes projetos educativos e de formação de professores, que vêm sendo desenvolvidos ao longo da história do Brasil. E também, evidencia a predominância das propostas de Educação Rural, bem como, a inoperância dessas políticas frente aos desafios educacionais do campo.

Nesse contexto, a Educação do Campo surgiu como uma fortaleza, com resistência ao modelo de desenvolvimento econômico capitalista; nasceu como uma proposta educativa alternativa para os trabalhadores do campo, fundamentada em seus objetivos de luta, necessidades e anseios. Evidenciamos que a negação da humanidade dessas populações, desde o processo de colonização, foi utilizada para justificar a exploração, hoje usada para negligenciar seus direitos e para perpetuar a desumanização dessas pessoas. A Educação do Campo reconhece os camponeses como humanos, como trabalhadores, que não aceitam a condição de consumidores de projetos de Educação Rural.

No que se refere às propostas destinadas à formação de professores, observamos que existem caracterizações específicas que diferem o Curso de Licenciatura em Educação do Campo das demais propostas desenvolvidas ou em desenvolvimento. A primeira delas diz respeito ao berço de nascimento. A LEdoC originou-se no seio dos movimentos sociais, delineando-se a partir de 
interesses e necessidades das populações camponesas, mediante seus projetos de vida, de sociedade e de politização, vislumbrando a emancipação dessas populações. As demais propostas de formação docente possuem caráter predominantemente estatal, geralmente desenvolvidas como políticas de governo, sob o viés ideológico, político e econômico dos governantes do país, considerando interesses, divergentes e contraditórios em relação ao campo e a seus sujeitos.

É bem verdade que, também, existem divergências em relação às concepções de campo. Para o cenário teórico-discursivo da Educação do Campo, o termo campo é tomado com sentido peculiar e diverso, conforme concebido por algumas propostas educativas, que concebem o campo como um espaço de possibilidades e de produção da vida em seus aspectos culturais, sociais, econômicos e políticos, nos quais se inscreveram resistência dos camponeses que lutam pelo acesso e permanência na terra. Nessa perspectiva, o termo campo não é concebido em oposição ao urbano, tampouco comporta apenas a produção de alimentos e riquezas, a exemplo do que concebiam propostas anteriores.

Outra diferenciação é que, enquanto a Educação do Campo se afirma como uma política pública integrante de um projeto de desenvolvimento social e econômico mais amplo, no qual a luta pela terra, pela habitação e pelas políticas sociais também fazem parte, os programas de Educação Rural objetivam, predominantemente, integrar as populações camponesas como parte de projetos governamentais, ora destinadas apenas à escolarização rudimentar das crianças e adultos, ora à formação docente de baixa qualidade e sem nenhuma vinculação com outros objetivos mais amplos. Comporta a ideia apequenada de espaço produtor de alimento e de riqueza de uma nação, estado ou região.

Ao contrário do exposto, a Educação do Campo delineia propostas educativas que objetivam condições de vida para o homem no seu habitat natural, o próprio campo, requerendo políticas públicas que abranjam todos os níveis educacionais, da Educação Infantil ao Ensino Superior, considerando as especificidades e a diversidade do povo camponês. Não se trata, propriamente, de pretender fixar o homem rural no campo, pois o processo educativo deve criar condições e oportunidades de desenvolvimento e realização pessoal e social, mas, de assegurar uma educação que atenda aos interesses e as necessidades sociais desses sujeitos, oferecendo condições àqueles que nele desejam permanecer e viver com dignidade.

A análise dos aspectos históricos evidencia que estamos vivendo um movimento de retrocessos em relação às conquistas sociais asseguradas pela Constituição Federal de 1988, convocando-nos para que, juntamente aos movimentos sociais, universidades e sociedade, lutemos pela garantia dos direitos conquistados e pelo avanço na implementação de políticas públicas que assegurem direitos elementares à cidadania, tais como: educação, saúde, habitação, saneamento, 
cultura, lazer, notadamente, assinalamos que as políticas de formação de professores para o campo devem ser uma dessas bandeiras de luta.

\section{REFERÊNCIAS}

ABRUCIO, F. L. Formação de professores no Brasil: diagnóstico, agenda de políticas e estratégias para a mudança. São Paulo: Moderna, 2016. Disponível em: < https://www.todospelaeducacao.org.br/biblioteca/1543/formacao-de-professores-no-brasil--diagnostico-agenda-de-politicas-e-estrategias-para-a-mudanca/ >. Acesso em: 07 jan. 2019.

ARAÚJO, F. M. L. Educação rural e formação de professores no Brasil: gênese de uma experiência pioneira. Cadernos de História da Educação, Uberlândia, v. 10, n. 2, p. 237-255, jul./dez., 2011. Disponível em: < http://www.seer.ufu.br/index.php/che/article/view/14624 >. Acesso em: 20 jul. 2019.

ARroyo, M. G. Pedagogia do Oprimido. In: CALDART, R. S. et al. (Orgs.). Dicionário de Educação do Campo. Rio de Janeiro; São Paulo: Escola Politécnica de Saúde Joaquim Venâncio; Expressão Popular, 2012. p. 553-560.

BRASIL. Constituição da República Federativa do Brasil. Brasília: Imprensa Oficial, 1988.

BRASIL. Lei n. 9.394, de 20 de dezembro de 1996. Lei de Diretrizes e Bases da Educação Nacional. Estabelece as Diretrizes e Bases da Educação Nacional. Diário Oficial da União, Brasília, DF, 24 dez. 1996. Disponível em: < http://portal.mec.gov.br/seed/arquivos/pdf/tvescola/leis/lein9394.pdf >. Acesso em: 27 out. 2019.

BRASIL. Ministério da Educação; Secretaria de Educação Continuada, Alfabetização e Diversidade. Referências para uma política de Educação do Campo: caderno de subsídios. Brasília, 2005.

BRASIL. CONSELHO NACIONAL DE EDUCAÇÃO (CNE). Relatório do Parecer $\mathbf{n}^{\mathbf{o}}$ 36/2001 - Câmara da Educação Básica do Conselho Nacional de Educação: Diretrizes Operacionais para a Educação Básica nas Escolas do Campo. Relatora: Edla de Araújo Lira Soares. Conselho Nacional de Educação / Ministério da Educação e Cultura. Aprovado em 04/12/2001. Brasília-DF, 2001.

BRASIL. Decreto $\mathbf{n}^{\mathbf{0}}$ 7.352, de 4 de dezembro de 2010. Dispõe sobre a Política Nacional de Educação do Campo e o Pronera. Brasília: Ministério da Educação, 2010. Disponível em: < http://www.planalto.gov.br/ccivil_03/_ato2007_2010/2010/decreto/d7352.htm >. Acesso em: 27 out. 2019.

CALDART, R. S. Pedagogia do Movimento Sem Terra. São Paulo: Expressão Popular, 2004.

CALDART, R. S. Pedagogia do Movimento. In: CALDART, R. S. et al. (Orgs.). Dicionário de Educação do Campo. Rio de Janeiro; São Paulo: Escola Politécnica de Saúde Joaquim Venâncio; Expressão Popular, 2012. p. 546-553. 
CORTEZ, B. C. Práticas de formação de professores de $1^{\text {a }}$ a $4^{\text {a }}$ série do ensino

fundamental: um estudo da formação do magistério leigo em Oeiras (PI-1970 a 2004). 2006. 135 f. Dissertação (Mestrado em Educação) - Centro de Ciências da Educação. Universidade Federal do Piauí, Teresina, 2006.

CUNHA, M. A. A. Guia do PROGRAMAÇÃo. Brasília: MEC. FUNDESVOLA, 2005. 58 p.

FARIAS, I. M. de. et al. Didática e docência: aprendendo a profissão. 3 ed. Brasília: líber Livro, 2011.

FREITAS, H. C. L. Formação de professores no Brasil: 10 anos de embate entre projetos de formação. Educ. Soc., Campinas, vol. 23, n. 80, p. 136-167, set., 2002. Disponível em: < http://www.cedes.unicamp.br >. Acesso em: 10 mai. 2017.

FUSARI, J. C. et al. A Educação Básica no Brasil. In: FUSARI, J. C.; PIMENTA, S. G.; ROBERT, M. I.; FERREIRA, M. J. A.; FUSARI, J. C. (Orgs.). O professor de primeiro grau: trabalho e formação. São Paulo: Edições Loyola, 1990. p. 32-38.

GONÇALVES, M. C. “Eu era professora, era catequista, era enfermeira, eu era tudo!”: a profissão docente no meio rural piauiense (1971-1989). 2015. 198 f. Tese (Doutorado em Educação) - Centro de Ciências da Educação. Universidade Federal do Piauí, 2015.

HEINZ, F. M. Do uso do Who’s Who e de outros dicionários biográficos na construção de biografias coletivas das elites sociais e políticas do Brasil contemporâneo. Barbarói, Santa Cruz do Sul, n. 10, p. 49-60, jan./jun., 1999.

KINCHELOE, J. L.; MCLAREN, P. Repensando a teoria crítica e a pesquisa qualitativa. In: DENZIN, N. K.; LINCOLN, Y. S. (Orgs.) O planejamento da pesquisa qualitativa: teorias e abordagens. Trad. Sandra Regina Netz. Porto Alegre: Artmed, 2006. p. 281-314.

LEITE, S. C. Escola rural: urbanização e políticas educacionais. São Paulo: Cortez, 2002.

LIBÂNEO, J. C. Educação escolar: políticas públicas, estrutura e organização. São Paulo: Cortez, 2012.

MATIJASCIC, M. Professores da Educação Básica no Brasil: condições de vida, inserção no mercado de trabalho e remuneração. Texto para discussão. Instituto de Pesquisa Econômica Aplicada, Brasília: Rio de Janeiro: Ipea, 2017. p. 09-18. Disponível em: <

http://www.ipea.gov.br/portal/index.php?option $=$ com content\&view $=$ article\&id $=30338>$. Acesso em: 05 mai. 2019.

MATOS, I. C. R. A concepção de educação em Sud Mennucci. 2004. 118 f. Dissertação (Mestrado em Educação) - Faculdade de Educação. Universidade Estadual de Campinas Campinas, 2004.

MOLINA, M. C. Expansão das licenciaturas em Educação do Campo: desafios e potencialidades. Educar em Revista, Curitiba, Editora UFPR, n. 55, p. 145-166, jan./mar., 2015.

MOLINA, M. C.; ANTUNES-ROCHA, M. I. Educação do Campo: história, práticas e desafios no âmbito das políticas de formação de educadores - reflexões sobre o PRONERA e o PROCAMPO. Revista Reflexão e Ação, Santa Cruz do Sul, v. 22, n. 2, p. 220-253, jul./dez., 
2014. Disponível em: < http://online.unisc.br/seer/index.php/reflex/index $>$. Acesso em: 22 out. 2019.

OLIVEIRA, M. M. Sequência didática interativa: no processo de formação de professores. Petrópolis: Vozes, 2013.

PALUDO, C. Educação Popular. In: CALDART, R. S. et al. (Orgs.). Dicionário de Educação do Campo. Rio de Janeiro; São Paulo: Escola Politécnica de Saúde Joaquim Venâncio; Expressão Popular, 2012. p. 280-285.

PIMENTA, S. G.; LIMA, M. S. L. Estágio e docência. São Paulo: Cortez, 2012.

PORTO, C. E. Roteiro do Piauí. Teresina: Ed. Artenova, 1974.

REIS, E. dos S. O projeto político-pedagógico nas escolas do campo: um instrumento essencial. In: LIMA, E. de S.; SILVA, A. M. da. (Orgs.). Diálogos sobre Educação do Campo. Teresina: EDUFPI, 2011. p. 173-188.

SANTANA, M. do P. S. C. B. A constituição da rede escolar e a prática das professoras primárias na zona rural do Piauí nos anos de 1940 a 1970. 2011. 178 f. Dissertação (Mestrado em Educação) - Centro de Ciências da Educação. Universidade Federal do Piauí, Teresina, 2011.

SAVIANI, D. Formação de professores: aspectos históricos e teóricos do problema no contexto brasileiro. Revista Brasileira de Educação, Rio de Janeiro, v. 14 n. 40, p. 143-155, jan./abr., 2009. Disponível em: < www.scielo.br/scielo.php?script=sci issuetoc\&pid=1413$\underline{247820090001 \ldots 1}>$. Acesso em: 12 mar. 2019.

SILVA, A. M. Educação do Campo: uma breve (re)construção epistemológica. In: LIMA, E. da S.; SILVA, A. M. da. (Orgs.). Diálogos sobre educação do campo. Teresina: EDUFPI, 2011. p. 63-87.

SILVA, C. A. P. da.; SOARES, J. M. R. (Orgs.). Plano Estadual de Educação do Piauí. Secretaria Estadual de Educação do Piauí, 2016.

SILVA, P. R. S. Outros campos: os movimentos sociais da Zona Costeira do Ceará como sujeitos da educação do campo. 2005. 75 f. Fortaleza: Monografia (Especialização em Educação do Campo e Desenvolvimento) - Universidade de Brasília, Brasília, 2005.

SOUZA, R. F. História dos professores rurais no Brasil: formação e profissionalização (1930 1970). In: VIII Congresso Brasileiro de História da Educação, Anais... Paraná, p. 97, 2015.

Disponível em: < www.ppe.uem.br/8cbhe/resumos/pdf/c coord/cc25.pdf $>$. Acesso em: 24 mai. 2019.

VIEIRA, M. A. B. A arte de desasnar crianças no sertão Piauí (1890-1930). S./d., p. 01-09. Disponível em: < http://www.sbhe.org.br/novo/congressos/cbhe5/pdf/381.pdf > . Acesso em: 04 nov. 2019. 